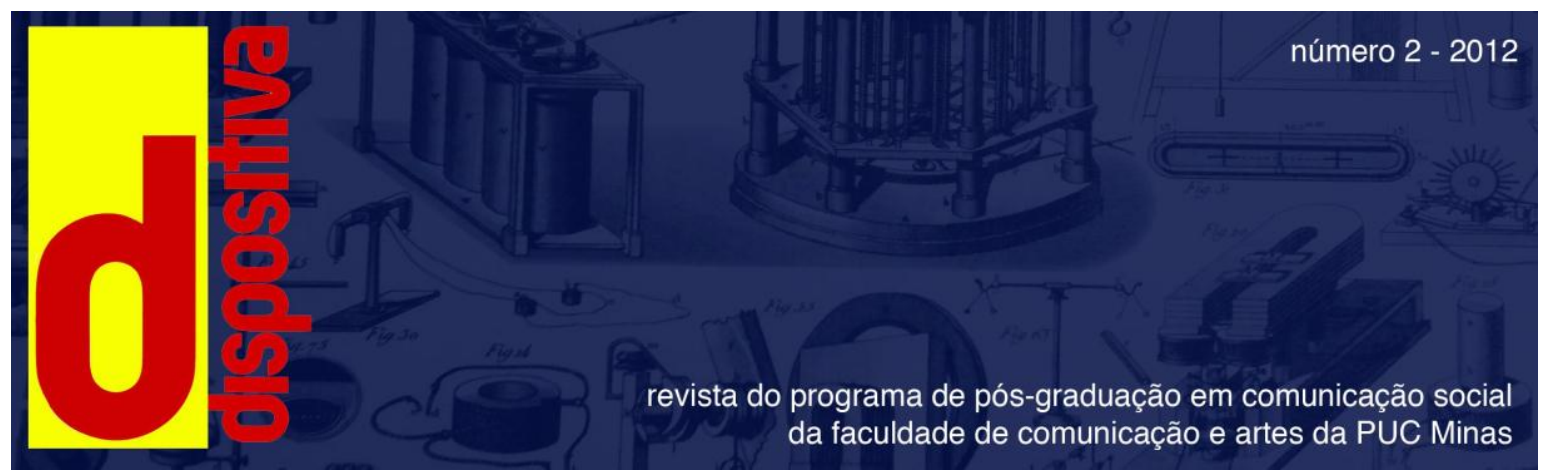

\title{
A Arte da Biografia // The Art of Biography
}

Texto de Virginia Woolf traduzido por Norida Teotônio de Castro ${ }^{1}$

\section{Resumo}

Em A arte da biografia, Virgínia Woolf apresenta mais do que uma importante recuperação sincrônica e diacrônica da biografia. O texto se coloca, antes, como um testemunho das intensas transformações sofridas pelo relato biográfico na Europa das primeiras décadas do século XX e, para além, um prenúncio da importância que as narrativas sobre o 'eu' alcançariam em todo o mundo ocidental. Woolf, que viveu os debates acerca da biografia, alerta para os muitos limites do trabalho biográfico, entendendo que a própria natureza do relato impõe circunstâncias inescapáveis ao biógrafo, entre elas a de dificilmente se estabelecer como verdadeiro trabalho artístico.

Palavras-chave: Biografias; arte; Virginia Woolf.

1 Doutora em Comunicação e Semiótica pela Pontifícia Universidade Católica de São Paulo (2000). Mestre em Psicologia pela Pontifícia Universidade Católica de Campinas (1993). Tem experiência docente nas áreas de Ciências da Saúde, Ciências Humanas e Sociais Aplicadas, em cursos de graduação e pós-graduação lato e stricto sensu. 
A arte da biografia, como costumamos dizer - e, então, prontamente nos perguntamos: a biografia é uma arte? A questão, talvez, seja simplória, mas, com certeza, não é irrelevante, considerando o intenso prazer que os biógrafos têm nos proporcionado. Mas a pergunta questiona a si mesma tão assiduamente que algo deve haver por trás dela. Isto é, em qualquer época que uma nova biografia é aberta, capturando uma sombra em suas páginas, parecendo fazer existir ali alguma uma coisa amortecida; da multiplicidade de biografias que são escritas, quão poucas sobrevivem, afinal de contas!

Mas o biógrafo poderia perguntar qual a razão para essa alta taxa de mortalidade. É que a biografia, comparada com artes como a poesia e ficção, é uma arte jovem. O interesse em nossos "eus" e em outras pessoas é um desenvolvimento tardio do pensamento humano. Até o século XVIII, na Inglaterra, tal curiosidade se expressou por meio da escrita de histórias sobre vidas de pessoas privadas. Somente no século XIX, a biografia passou a ser produzida mais intensamente. Nessa época, houve somente três grandes biógrafos - Johnson, Boswell, e Lockhart. Uma explicação para isso foi o seu curto tempo; e a justificativa corroborada por esses trabalhos é de que a arte da biografia teve pouco tempo para se estabelecer e se desenvolver. É tentador o desafio de buscar compreender a razão - por que o sujeito que escreve um livro de prosa se tornou, tantos séculos após, no sujeito que escreve um poema? Entender por que Chaucer precedeu Henry James. Melhor deixar esta questão insolúvel e sem resposta e seguir para a próxima: a falta de obras primas. É que a arte da biografia é a mais restrita de todas as artes. Tem-se como prova disso o prefácio de Smith, que escreveu a vida de Jones. Ele usou a oportunidade para agradecer a velhos amigos que lhe emprestaram cartas, e "por último, mas não por menos", à Sra. Jones, a viúva, pela ajuda, "sem a qual”, como ele menciona, "essa biografia não poderia ter sido escrita". Ali, o novelista diz em seu prefácio: “cada personagem nesse livro é fictício". O novelista é livre, o biógrafo é amarrado.

Vamos, ainda, de encontro a uma questão que já vem de longe e que, novamente, mostra-se de grande dificuldade e talvez insolúvel: o que queremos dizer ao chamar um livro de obra de arte? De qualquer modo, há uma distinção entre biografia e ficção elas se diferem na própria substância da qual são feitas. Uma é escrita com a ajuda de amigos, fatos; já a outra é criada sem quaisquer restrições, salvo aquelas que o artista, por razões que lhe parecem interessantes, escolhe obedecer. Esta é uma distinção, e há 
uma boa razão para pensar que, no passado, os biógrafos a encontraram não só como uma distinção, mas como uma distinção muito cruel.

A viúva e os amigos foram senhores severos. Supõe-se, por exemplo, que o homem genioso era imoral, de temperamento doentio, e jogava as botas na cabeça da criada. A viúva diria ao biógrafo: "ainda assim eu o amava - ele foi o pai dos meus filhos; e o público que ama seus livros não deve, por nada, ser desiludido. Cubra... Omita...”. O biógrafo obedeceu. E assim, a maioria das biografias vitorianas é como as figuras de cera preservadas na Abadia de Westminster, que são carregadas em procissões de funerais pela rua - efígies que têm somente uma lisa e superficial semelhança com o corpo no caixão.

Já no final do século XIX, houve uma mudança. De novo, por razões não fáceis de descobrir, viúvas passaram a ter a mente mais aberta, o público, com uma visão mais aguçada; a efígie já não mais carregava convicção e nem satisfazia a curiosidade. $O$ biógrafo certamente conquistou mais liberdade. Ele poderia sugerir, pelo menos, que havia cicatrizes e sulcos no rosto do homem morto. Carlyle de Foude não é, de modo algum, uma máscara de cera pintada de vermelho rosado. Na sequência de Foude, houve Sir Edmund Gosse, que ousou dizer que seu próprio pai foi um ser humano falível. E seguindo Edmund Gosse, nos primeiros anos do presente século ${ }^{2}$, surgiu Lytton Strachey.

O escritor Lytton Strachey é uma figura tão importante na história da biografia que merece aqui uma pausa. Seus três famosos livros: Vitorianos eminentes, Rainha Victoria e Elizabeth e Essex, mostram ambas as dimensões: o que uma biografia pode e não pode fazer. Elas sugerem muitas respostas possíveis para a questão se uma biografia é arte, e se não, porque ela fracassa. Lytton Strachey nasceu como autor em um momento de sorte. Em 1918, quando fez sua primeira tentativa de escrever uma biografia, esta já se mostrava como uma forma que oferecia muitos atrativos, em função das novas liberdades que passou a permitir. Para um escritor como ele, que tinha desejado escrever poesia e peças teatrais, mas tinha dúvidas quanto o seu próprio poder criativo, a biografia parecia ser uma alternativa promissora. Finalmente, era possível dizer a verdade a respeito do morto; e a época vitoriana era rica em figuras notáveis, muitas das quais tinham sido grosseiramente deformadas pelas efígies engessadas

\footnotetext{
${ }^{2}$ Nota de tradução: Virgínia Woolf refere-se ao Século XX.
} 
criadas anteriormente sobre elas. Recriá-las, mostrá-las como realmente foram, era uma tarefa que exigia talento semelhante ao de um poeta ou de um novelista, ainda que não pedisse aquele poder inventivo - que Strachey acreditava que lhe faltava.

E valeu a pena ter tentado. A raiva e o interesse que seus curtos estudos sobre os Vitorianos Eminentes despertaram, mostraram que ele era capaz de fazer Manning, Florence Nightingale, Gordon e todo o resto viver como nunca tinham vivido enquanto estiveram encarnados. Mais uma vez, eles eram o centro de um zumbido de discussão. Gordon realmente bebia, ou isso era uma invenção? Florence Nightingale recebera a Ordem de Mérito em seu quarto ou em sua sala de estar? Ele agitou o público, apesar dos tumultos já existentes oriundos da guerra européia, com um espantoso interesse em tais pequenos assuntos. Raiva e risos se misturaram, edições se multiplicaram.

Mas esses curtos estudos se caracterizam pela ênfase e abreviação próprias de caricaturas. $\mathrm{Na}$ vida das duas grandes rainhas, Elizabeth e Victoria, ele tentou uma tarefa bem mais ambiciosa. A biografia nunca tivera uma chance tão propícia de mostrar o que poderia fazer. Estava sendo testada por um escritor que era capaz de fazer uso de todas as liberdades por ela conquistadas. Ele era destemido, provou seu brilhantismo e mais, havia aprendido o seu trabalho. O resultado acabou refletindo sobre a natureza da própria biografia. Quem duvida, após ler os dois livros novamente, um após o outro, de que "Victoria" é um sucesso triunfante, e "Elizabeth", por comparação, é um fracasso? Mas também parece, ao compará-las, que não foi Lytton Strachey que fracassou, foi a arte da biografia. Em "Victoria", ele tratou a biografia como um ofício, e se submeteu as limitações do mesmo, já em "Elizabeth" ele a tratou como uma arte e desprezou suas limitações.

Mas devemos continuar a nos perguntar como chegamos a esta conclusão e quais razões a justificam. Em primeiro lugar, é claro que as duas Rainhas apresentam problemas muito diferentes para o seu biógrafo. Tudo que a Rainha Victoria fazia e pensava era matéria de conhecimento comum. Ninguém fora tão intimamente checado e precisamente autenticado como ela. O biógrafo não poderia inventá-la, porque a qualquer momento algum documento estaria à mão para checar sua invenção. E, ao escrever a respeito de Victoria, Lytton Strachey se submeteu a essas condições. Ele usou o poder que tem o biógrafo de selecionar e de relacionar informações. Entretanto, ele se manteve estritamente no mundo dos fatos. Cada afirmativa foi verificada, cada fato foi autenticado. E o resultado é uma vida que, muito possivelmente, fará pela velha Rainha o que Boswell fez pelo velho elaborador de dicionários. Em tempos por vir, 
Rainha Victoria, de Lytton Strachey, será a Rainha Victoria, assim como Johnson de Boswell é agora o Dr. Johnson. As outras versões perderão a importância e desaparecerão. Isso foi uma extraordinária façanha e, sem dúvida, depois de concluí-la, o autor estava ansioso por ir mais longe. Surgiu da biografia, a Rainha Victoria sólida, real, palpável, mas que indubitavelmente era limitada. Não poderia a biografia produzir algo da intensidade da poesia, algo da excitação do drama, e manter ainda a virtude particular que pertence ao fato - sua realidade sugestiva, sua própria criatividade?

A Rainha Elizabeth pareceu emprestar a si mesma perfeitamente a este experimento. Muito pouco se conhecia a seu respeito. A sociedade em que ela viveu era tão remota que os hábitos, os motivos, e até as ações das pessoas daquela época eram plenos de estranheza e obscuridade. "Por qual arte havemos de esburacar nosso caminho adentro daqueles estranhos espíritos? Por aqueles ainda mais estranhos corpos? Quanto mais claramente os percebemos, mais remoto aquele universo se torna", comentou Lytton Strachey em uma das primeiras páginas. Ainda assim, havia uma "história trágica" permanecendo adormecida, meio revelada, meio oculta, na história da Rainha e de Essex. Tudo parecia se emprestar à feitura de um livro que combinava as vantagens de ambos os mundos. Isto deu ao artista liberdade para inventar, mas auxiliou sua invenção com o suporte de fatos - um livro que não era somente uma biografia, mas também um trabalho de arte.

Não obstante, a combinação se mostrou impraticável; fato e ficção se recusaram a misturar-se. "Elizabeth" nunca se tornou real como a Rainha Victoria tinha sido, mas, nem fictícia, no sentido em que Cleópatra ou Falstaff é ficção. A razão poderia ser que muito pouco era conhecido - e o autor foi convidado a inventar - e ainda assim alguma coisa era conhecida, e sua invenção foi checada. A Rainha se move, assim, em um mundo ambíguo, entre fato e ficção, nem encarnada, nem desencarnada. Há uma sensação de indefinição e de esforço, de uma tragédia que não tem crises, de personagens que se encontram, mas não se chocam.

Se esse diagnóstico é verdadeiro, somos forçados a dizer que o problema está na própria biografia. Ela impõe condições que devem ser baseadas em fatos, que podem ser verificados por outras pessoas além do artista. Se o autor inventa fatos como um artista os inventa - fatos que ninguém mais pode verificar - e tenta combiná-los com fatos de outra sorte, eles destroem um ao outro. 
Parece que o próprio Lytton Strachey, em Rainha Victoria, se deu conta das imposições dessa condição e se rendeu a ela instintivamente. "Os quarenta e dois primeiros anos da vida da Rainha", ele escreveu, "estão iluminados por uma grande e variada quantidade de informação autêntica. Com a morte de Albert, um véu desce". E com a morte de Albert, quando o véu desceu e a autêntica informação falhou, ele sabia que o biógrafo deveria seguir o exemplo. "Devemos estar contentes com uma breve e resumida narrativa", ele escreveu; e o último ano é brevemente descartado. Mas, o todo da vida de Elizabeth foi vivido atrás de um véu bem mais espesso do que os últimos anos de Victoria. E ainda, ignorando sua própria constatação, ele continuou a escrever, não uma breve e sintética narrativa, mas um livro inteiro acerca daqueles espíritos estranhos e até estranhos corpos a respeito de quem faltava a informação autêntica.

III

Parece-nos que quando um biógrafo se queixa de estar cercado por amigos, cartas e documentos, ele está colocando seu dedo sobre um elemento necessário na biografia; e que é também uma limitação necessária. Porque as personagens inventadas vivem em um mundo livre onde os fatos são verificados por uma única pessoa - o próprio artista. Sua autenticidade reside na verdade de sua própria visão. $\mathrm{O}$ mundo criado por esta visão é mais raro, mais intenso, e mais inteiramente parte do mundo que é largamente feito de informação autêntica suprimida por outras pessoas. E por causa dessa diferença, os dois tipos de fatos não se misturarão. Se eles se tocam, eles se destroem. Nenhum pode fazer o melhor dos dois mundos, parece ser a conclusão: você deve escolher, e deve se conformar com a sua escolha.

Mas, apesar da falta de êxito de Elizabeth e Essex levar a essa conclusão, esse fracasso abriu caminho para descobertas posteriores - porque foi resultado de um experimento ousado realizado com habilidade magnífica. Se Lytton Strachey vivesse, ele exploraria sem dúvida a veia que ele próprio abriu. Desse modo, ele nos mostrou o caminho no qual outros podem avançar. O biógrafo é ligado por fatos. Mas, se assim é, ele deve ter o direito a todos os fatos disponíveis. Se Jones jogou as botas na cabeça da criada, tinha uma amante em Islington, ou foi encontrado bêbado na sarjeta após uma noite de orgia, ele deve ser livre para assim dizer - na medida mínima em que a lei da difamação e o sentimento humano permitem.

Mas estes fatos não são fatos da ciência - que, uma vez descobertos, se colocam sempre como os mesmos. Eles estão sujeitos a mudanças de opinião, que se alteram à medida 
que os tempos mudam. O que foi pensado como um pecado é agora conhecido - porque a luz dos fatos nos foi conquistada pelos psicólogos - como um infortúnio; talvez uma curiosidade; talvez nem um nem outro, mas como uma insignificante fraqueza de menor importância. A ênfase no sexo tem se transformado no campo da memória viva. Isto leva à destruição de uma grande porção de matéria morta, obscurecendo as verdadeiras características da face humana. Muitos dos velhos títulos de capítulos - vida escolar, casamento, carreira - são exibidos com distinções muito arbitrárias e artificiais. O curso real da existência do herói tomou, muito provavelmente, um curso diferente.

Portanto, o biógrafo deve ir à frente do resto de nós, como o canário do mineiro testando a atmosfera, detectando falsidades, irrealidades, e a presença de convenções obsoletas. Seu senso de verdade deve estar vivo e na ponta dos dedos. E, novamente, desde que vivemos em um tempo em que mil câmeras estão apontadas por jornais, cartas e diários, de todos os ângulos, em direção a cada personagem, ele deve estar preparado para admitir versões contraditórias a respeito de uma mesma face. A biografia ampliará seu escopo mediante a visada escrutinadora de pontos embaraçosos. E dessa diversidade toda surgirá não uma vida desordenada, mas uma unidade mais rica. E, novamente, a partir do momento em que se passa a ser conhecer muito daquilo que costumava ser desconhecido, a questão inevitavelmente pergunta a si mesma, onde as vidas dos grandes homens deveriam ser registradas? Não é qualquer um que viveu uma vida e deixou um registro desta, que é merecedor de uma biografia - os fracassos bem como os sucessos, o obscuro tanto quanto o ilustre. E o que é grandeza? E o que é pequenez? Devemos revisar nossos padrões de mérito e estabelecer novos heróis para nossa admiração.

IV

A biografia, portanto, está somente em início de carreira. Tem ainda uma vida longa e ativa diante de si, temos certeza - uma vida cheia de dificuldades, perigo e trabalho árduo. Entretanto, podemos também estar seguros de que se trata de uma vida diferente da vida da poesia e da fícção - uma vida vivida em um degrau mais baixo de tensão. E, por essa razão, suas criações não são destinadas à imortalidade que o artista de vez em quando atinge mediante suas criações.

Parece já existir certa prova disto. Até Dr. Johnson tal como criado por Boswell não viverá tanto quanto Falstaff tal como criado por Shakespeare. Micawber e Srta. Bates, podemos estar certos, sobreviverão a Sir Walter Scott, de Lockhart, e à Rainha Victoria, 
de Lytton Strachey. Porque eles são feitos de matéria mais duradoura. A imaginação do artista na sua mais alta intensidade acende o que é perecível em fato; ele constrói com o que é durável; mas o biógrafo deve aceitar e construir com o perecível, incrustá-lo bem no tecido de seu trabalho. Muito perecerá, pouco sobreviverá. E assim chegamos à conclusão de que, se ele é um artífice, não um artista; seu trabalho não é um trabalho de arte, mas algo intermediário e localizado entre ambos.

Mesmo assim, neste nível inferior, o trabalho do biógrafo é inestimável. Não há como agradecer-lhe suficientemente pelo que faz por nós. Porque somos incapazes de viver completamente no intenso mundo da imaginação. A imaginação é uma faculdade que logo cansa e precisa de descanso e refresco. Mas para uma imaginação cansada, o alimento apropriado não é poesia nem ficção de valor menor - de fato elas a neutralizam e dela debocham. Mas é o fato sóbrio, aquela "informação autêntica" da qual, como Lytton Satrachey nos mostrou, uma boa biografia é feita. Quando e onde o homem real viveu, como era sua aparência, se ele usava botas de amarrar ou de elástico na lateral, quem eram suas tias e seus amigos, como ele assuava o nariz, quem ele amava e como e quando ele veio a morrer, morreu em sua cama como um cristão, ou...

Ao nos relatar os fatos reais, separar o pequeno do grande, e formatar o todo, de modo que percebamos o contorno, o biógrafo faz mais para estimular a imaginação do que qualquer, salvo os melhores, poeta ou novelista. Porque poucos poetas ou novelistas são capazes do alto grau de tensão que nos proporciona a realidade. Mas praticamente qualquer biógrafo, se ele respeita os fatos, pode nos proporcionar muito mais do que um fato para adicionar à nossa coleção. Ele pode nos oferecer o fato criativo; o fato fértil; o fato que sugere e gera. Disto, também, há certa prova. Porque, com alguma frequência, quando uma biografia é lida e posta de lado, algumas cenas permanecem claras, algumas figuras vivem nas profundezas da mente e ainda nos provocam; um poema ou um romance, quando os lemos, sentimos um início de reconhecimento, como se nos lembrássemos de algo que já conhecemos. 